\title{
Analysis on Role of Project Contract Management in Prevention of Project Risks Hongmei Liu
}

Institute of Technology, Jiangsu Open University, Nanjing, 210036, China

Keywords: project management; project risk; prevention measures; role analysis

\begin{abstract}
Enterprise contract management means the organized and planned signing and management of contract by enterprises in order to achieve the development of economy. The complex development of building enterprises increases the difficulty of contract management, making the contract management of enterprises more important. Due to long construction period and more influential factors in the building project, the project risks also appear. Implementing contract management can reduce the risks of development of building enterprises ensure that the enterprises can obtain stable income in the fierce market competition, analyze the risks appearing in the building project contract in the current stage, strictly prevent the actual risk problems and take risk prevention measures through the contract management. In this paper, the project contract risk and relevant management measures are researched and analyzed.

Risk means the situation that might occur in the specific condition and time, which mainly refers to the difference from the expected objective, including two aspects, i.e. to bring profit to the development of enterprises, and also bring great problems. Therefore, to control the risks and improve development benefit of enterprises, it is required to manage the risks. Risk is objective, so it is required to face and control risks and minimize their negative influence on the development of enterprises. For the building project, due to long construction period, ever-changing projects and more factors involved in the project contract, there are many risks existing in the project contract. Therefore, managing the risks of building enterprises while managing contract has become a focus in the management.
\end{abstract}

\section{Factors of contract risks}

The risk in contract exists in each link of the contract cycle, from contract signing, implementation, modification, transfer to termination. From these aspects, the factors causing the contract risks can be classified into objective factor, subjective factor, management factor and artificial factor.

(I) Objective factor

Objective factor refers to the external factor causing the occurring of risk in the process of contract management, mainly including factor of economic environment change, national policy factor, legal factor, natural factor and other uncontrollable factors, the factor of economic environment will change with the international financial pattern, development of market economy and social form etc. Enterprises can effectively avoid risks by forecasting and analyzing the form and situation when signing the contract. Policy and law are the means for macro economic control and adjustment of currency and finance etc. according to the national economic development and social situation. The adjustment contents can be collected and prevented within a certain range and have higher controllability compared with the change of market economy. Natural factor is the most difficult to control in management, with a strong contingency of occurring, and it is difficult to be forecasted and prevented in advance. Therefore, it can be avoided by transferring risks during the signing and implementation of contract.

(II) Subjective factor

The subjective factor causing the management risk is the prevention and management awareness to risks, mainly including the prevention to contract risk awareness, legal awareness and management responsibility awareness etc. Risk awareness means prevention awareness degree and 
concern degree to the risks existing in the contract and whether to prevent the risks necessarily. Legal factor means the degree of familiarity to relevant laws, whether to carefully audit and consider the contract details, whether to conform relevant provisions in laws and avoid the risks in legal contract during the contract establishment and implementation. Responsibility management awareness means the subjective awareness degree to the contract management and control. The poor risk control awareness of the managers will cause poor risk control effect, so as to bring great risks to the contract management.

(II) Management factor

The contract management system is the main factor in the current contract risk, and also the key factor, which includes the contract audit, cost calculation, amount system, settlement and other related system factors. The contract audit system risk means that the enterprises cannot carry out audit according to the relevant audit standards and procedures, contents and timeliness during the contract audit, causing that the contract cannot be signed normally or has problem during implementation. The cost risk factor includes the failure to conduct analysis and settlement according to relevant cost, so as to increase the enterprise operation risk; payment risk means that some building companies fails to pay the amount according to the contract or use the amount at will, cannot timely settle the subcontract or classified building amount, causing risk in the project finance; settlement system risk means that relevant settlement system is imperfect, causing that the completed project cannot be settled in timely, thus influencing the building income of the enterprises.

(IV) Artificial factor

Artificial factor means the factor of manager quality in contract management, and also the main factor in the contract risk management, including the management knowledge and level of the managers. The managers should understand the enterprise contract knowledge in detail, but due to more people, simple personnel structure knowledge, no sensitivity to the change form of social result and untimely prevention to the potential hazardous factors, there is a great risk in the process of contract signing and implementation. Management level means that the managers are incapable of controlling the contract, cannot discover the problems existing in the contract timely, or propose key opinions to the questions and cannot adopt the risk avoiding suggestions proposed by the auditor during contract draft, causing risks occurring in the contract management process.

\section{Importance of contract management in building}

First, the contract management can regulate the regulation and make the contract legally effective. According to the requirements of contract law of China, a written contract must be signed in construction, therefore, the contract management can reduce the risks during enterprise operation and ensure the development benefit of enterprises. During the contract signing, it is required to audit the qualification of signing parties, examine and approve the contract terms and concern the contract notices etc. Second, it can ensure the smooth performance of contract. There might be many difficulties encountered in construction, which requires to modify the contract. Through the contract management, it is possible to timely trace the contract implementation condition, timely discover the deviation occurring in contract establishment and actual operation, take measures to reduce contract dispute and both parties should negotiate more to ensure the maximum economic benefit of each other. Besides, it is beneficial for the analysis of contract quality. After signing of contract, both parties should perform the contract according to the responsibilities, in order to ensure the smooth proceeding of the contract, the enterprises should evaluate the contract quality and difficulty and improve the contract quality. In the process of evaluation, it is required to ensure that each item of the contract is actually implemented, so as to ensure the smooth proceeding of the building project. Finally, ensure the scientific management. The contract management both includes the fixed part and variable part. Therefore, enterprises should establish a scientific management inquiry system and timely collect relevant contract data. For each contract change and relevant communication, it is required to form a written report, make record and filing. The contract management is a key part in the enterprise management, so enterprises should be fully aware of its 
importance, so as to minimize the contract risk.

\section{Problems existing in the current contract management}

(I) Unregulated contract signing

The contract negotiation and singing of construction project are mainly in the form of bidding. The bidding documents are of strong legality, for the purpose of legally controlling and restricting the project construction, including construction schedule, project quality and construction fund management etc., but in the actual work, the bidding and bid invitation documents restricting the project contract often formalized too much, making the contract management inconsistent with the management of bidding and bid invitation document, and that the construction enterprises cannot timely master the project progress. Some contents in the bidding and bid invitation specify and restrict the construction contract, but many contents are not reflected in the contract, making many defects exist in the contract, and both parties have difference in the contract performance, the responsibility attribution is not clear, and it is difficult to solve the problems.

(II) The contract is complicated with great arbitrariness

The construction projects contain many complicated factors, and the construction project cycle is long, the total project quantities are difficult to be determined, the design is easy to be out of link with the construction, there is problem in building material and the construction period is delayed etc., all these factors will change the project contract. The contract of construction project covers the whole cycle, and the problem occurring in any link will cause the change of contract, this makes there is great arbitrariness in the modification of contract. The unregulated contract text record or the loss of data will make it impossible for the enterprises to timely master the implementation of project contact.

(II) Delayed performance of contract

The reasons for the delayed performance of contract in the construction project mainly include the following, the first is the design problem, the design drawing of building is not sent to the construction site timely, which influences the project execution degree, or the crossed construction makes each part of the project mutually restrict, and this influences the total project progress. Second, there is a lack of basic condition in the building project, the technology of the construction personnel cannot meet the demand of the current construction, and besides, there are more construction projects, it is unable to meet the construction of all parts when assigning the organization tasks, the construction personnel are not allocated reasonably, and this makes it unable to complete the construction period and influences the performance of contract.

\section{Measures for risk prevention in project contract management}

(I) Establish a perfect management system

When managing the project, the construction enterprises should put the professional management in the core position, and make the contract management play the link role in the whole management system, so that the construction of enterprises is strongly organized, thus ensuring the smooth proceeding of project construction. In the process of contract management, the essential part to determine the management effect is to control and manage the project comprehensively and from many aspects, the construction unit should fully master each link of the contract, control the problem tat might occur in the construction of project, if the project needs to be changed, it is required to obtain the joint audit of relevant departments, and during the change, both parties should jointly at present, the contract should be changed after analysis, and it is required to avoid the contract risk timely. In case of dispute, it is required to interpret and treat in a unified manner, protect the maximum benefit of either party by paw and relevant units should cooperation in the management.

(II) Strengthen the contract risk management awareness of enterprises

During the contract negotiation and signing, the contract principal should sort the negotiation contents and contract text together, and transfer the important contents in the bid invitation and 
bidding documents to the contract. During the contract negotiation, it is required to strengthen the risk awareness of contract parties, reasonably control the risk that might occur in construction, for example adjust the building material, building expense and labor cost in a unified manner and clearly specify the link where problems might occur. In the management of price etc., it is required to fully consider the interest of contract parties and create a harmonious signing atmosphere. Before construction, the enterprises should evaluate and explain the contract risks and prevent risks maximally during contract.

(II) Strengthen dynamic management in contract performance

The contract performance process contains the whole construction cycle. In the construction project, there will be many problems influencing the construction, so it is easy to cause contract problems and delay the contract. During construction, the enterprises should strengthen basic management of contract and negotiate with each construction department well, regularly investigate and report the contract performance, establish the preventive measures in the next construction, so that the contract can proceed smoothly. Each link of construction enterprises contain important management part, so it is required to control the risks from building quality, technical construction personnel, building technology and many other aspects, so as to improve the contract management system and increase the comprehensive management ability of enterprises.

(IV) Analyze the contract performance condition objectively

The construction unit should reasonably analyze the problems occurring in contract, the dispute occurring should be settled timely, so as to ensure the smooth performance of project contract. It is required to strengthen the communication between building unit and construction departments, explain and solve the contract problems in detail and take necessary measures for prevention, so that the contract can serve the building construction better.

(V) Contract transfer risk

During the contract management, it is possible to adopt claim system, so as to maintain the own interest of the contractor which is included in the whole project. The construction stage should be controlled as a key point, and relevant elements involved in the contract performance should be restricted. Some complicated construction projects should be reasonably subcontracted. According to different building technologies and project inspections etc., the contractor can unite with other professional building teams, so as to subcontract the project in a targeted manner and jointly undertake the project risk.

\section{Conclusion}

Contract is an important part in the development of market economy. A good contract can effectively supervise the market behavior and ensure the normal running of economy. The building project is very complicated, and it is difficult to control its construction. Therefore, there will be many risks existing in the building project contract. The construction enterprises should risk and prevent the risk, fully estimate the risks, establish an effective management mechanism and implement dynamic management in the performance of contract, so as to ensure the smooth development of enterprises' construction project, strengthen risk control and contract management and develop the construction enterprises better.

\section{References}

[1] Wang Qun, Research on Contract Contact Risk Management of Construction Enterprises [D] Southwest Jiaotong University, 2013

[2] Zhang Hui, Analysis of and Preventive Measures for Contract Risks of Construction Project [J], Science \&Technology Information, 2012 (10)

[3] An Qun, Brief Discussion on Analysis of and Preventive Measures for Contract Management of 
Construction Project [J], Doors and Windows, 2013 (8)

[4] Wan Lin, Zhu Lina, Liu Qiang, Analysis of Risk Management of Project Contract [J] SME Management and Technology (late issue), 2009 (8)

[5] Ye Ying, Brief Discussion on Risk Management and Supervision Measures for Construction Project Contract [J] Cost of Water Conservancy and Hydraulic Projects, 2010 (4). 